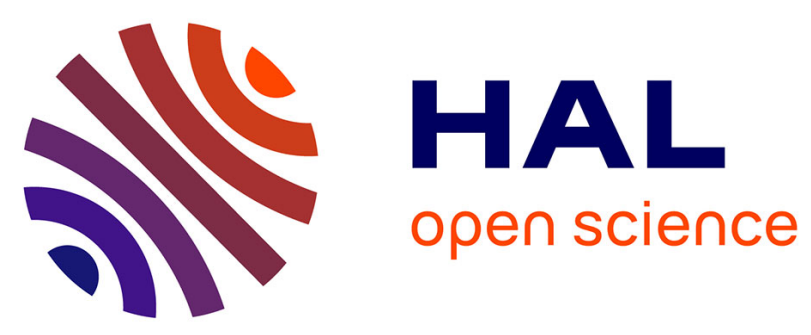

\title{
Lipoprotein-associated phospholipase A activity is increased in patients with definite familial hypercholesterolemia compared with other forms of hypercholesterolemia
}

\author{
Alessandro Mattina, David Rosenbaum, Randa Bittar, Dominique \\ Bonnefont-Rousselot, Davide Noto, Maurizio Averna, Eric Bruckert, Philippe \\ Giral
}

\section{- To cite this version:}

Alessandro Mattina, David Rosenbaum, Randa Bittar, Dominique Bonnefont-Rousselot, Davide Noto, et al.. Lipoprotein-associated phospholipase A activity is increased in patients with definite familial hypercholesterolemia compared with other forms of hypercholesterolemia. Nutrition, Metabolism and Cardiovascular Diseases, 2018, 28 (5), pp.517-523. 10.1016/j.numecd.2018.01.012 . hal-01821621

\section{HAL Id: hal-01821621 \\ https://hal.sorbonne-universite.fr/hal-01821621}

Submitted on 22 Jun 2018

HAL is a multi-disciplinary open access archive for the deposit and dissemination of scientific research documents, whether they are published or not. The documents may come from teaching and research institutions in France or abroad, or from public or private research centers.
L'archive ouverte pluridisciplinaire HAL, est destinée au dépôt et à la diffusion de documents scientifiques de niveau recherche, publiés ou non, émanant des établissements d'enseignement et de recherche français ou étrangers, des laboratoires publics ou privés. 


\title{
Lipoprotein-associated phospholipase $A_{2}$ activity is increased in patients with definite familial hypercholesterolemia compared with other forms of hypercholesterolemia.
}

\author{
Alessandro Mattina ${ }^{\text {a,b,e }}$, David Rosenbaum ${ }^{\mathrm{a}, \mathrm{b}, \mathrm{f}}$, Randa Bittar ${ }^{\mathrm{d}}$, Dominique Bonnefont- \\ Rousselot $^{\mathrm{d}, \mathrm{g}, \mathrm{h}}$, Davide Noto ${ }^{\mathrm{e}}$, Maurizio Averna ${ }^{\mathrm{e}}$, Eric Bruckert ${ }^{\mathrm{a}, \mathrm{c}}$, Philippe Giral $^{\mathrm{a}, \mathrm{c}}$
}

${ }^{a}$ Department of Endocrinology and Cardiovascular Disease Prevention; La Pitié-Salpêtrière-Charles Foix University Hospital (AP-HP), 48-83 boulevard de l'Hôpital, 75651 Paris Cedex 13, France.

bSorbonne University, UPMC Univ Paris 06, INSERM 1146, - CNRS 7371, Laboratoire d'imagerie Biomédicale, 91 boulevard de l'Hôpital, 75013, Paris, France.

${ }^{\mathrm{c}}$ Dyslipoproteinemia and Atherosclerosis Research Unit, UMRS 939, National Institute for Health and Medical Research (INSERM) and Pierre et Marie Curie University (UPMC - Paris VI), 48-83 boulevard de l'Hôpital, 75651 Paris Cedex 13, France.

${ }^{\mathrm{d}}$ Department of Metabolic Biochemistry, La Pitié-Salpêtrière-Charles Foix University Hospital (AP-HP), 48-83 boulevard de l'Hôpital, 75651 Paris Cedex 13, France

${ }^{\mathrm{e}}$ Department of Biomedicine, Internal Medicine and Medical Specialties, Division of Internal Medicine and Genetic Dyslipidemias, University of Palermo, via del Vespro, 131, 90127, Palermo, Italy.

fImaging Core Lab, Institute of Cardiometabolism and Nutrition, ICAN, 48-83 boulevard de l'Hôpital, 75651

Paris Cedex 13, France.

${ }^{g}$ Department of Biochemistry, Faculty of Pharmacy, Paris Descartes University, 4 avenue de l'Observatoire, 75006 Paris, France.

${ }^{\text {h } C N R S ~ U M R 8258 ~-~ I N S E R M ~ U 1022, ~ F a c u l t y ~ o f ~ P h a r m a c y, ~ P a r i s ~ D e s c a r t e s ~ U n i v e r s i t y, ~} 4$ avenue de

l'Observatoire, 75006 Paris, France.

\section{Corresponding author:}

Dr Alessandro Mattina

Unité de Prévention Cardiovasculaire, Service d'Endocrinologie Métabolisme, Pôle Cardiologie et Métabolisme, Groupe Hospitalier Pitié-Salpêtrière, Assistance Publique-Hôpitaux de Paris, 83, boulevard de l'Hôpital, 75651 Paris Cedex 13, France.

Tel: +33 (0)7 52558301 / + 39380 2599996, FAX: +33(0) 1421778 32,

E-mail: alessandromattina@gmail.com 


\title{
SHORT TITLE
}

\section{Lp-PLA $A_{2}$ activity in definite FH and non-definite FH hypercholesterolemic subjects}

\begin{abstract}
Background: Lipoprotein-associated phospholipase $\mathrm{A}_{2}$ (Lp-PLA $\mathrm{A}_{2}$ ) plays a key role in atherosclerosis development. It is considered a marker of increased risk of cardiovascular disease (CVD) and plaque vulnerability. Familial hypercholesterolemia (FH) is a genetic disorder characterized by elevated plasma levels of low-density lipoprotein cholesterol and a higher prevalence of early CVD.
\end{abstract}

Objective: Our aim was to evaluate the differences in Lp-PLA 2 activity in a population of hypercholesterolemic patients with and without definite FH.

Methods: Hypercholesterolemic patients were consecutively recruited. Definite FH was defined according to Dutch Lipid Clinic Network criteria $\geq 8$. All patients underwent routine clinical examination and biological assessments and Lp-PLA 2 activity was measured in blood samples.

Results: Among 469 patients, 118 had a definite diagnosis of FH. Lp-PLA 2 activity was significantly higher in definite FH patients compared to non-definite FH patients $(206.5 \pm$ 54.5 vs. $180.8 \pm 48.4 \mathrm{nmol} / \mathrm{min} / \mathrm{mL}, \mathrm{p}<0.0001)$. Lp-PLA 2 positively correlated with total cholesterol, LDL-C and apolipoprotein B and negatively with HDL-C and apolipoprotein A1. In multivariate analysis, definite $\mathrm{FH}$ diagnosis, LDL-C, HDL-C and statin treatment remained correlates of Lp-PLA 2 independently of systolic blood pressure.

Conclusions: Lp-PLA 2 activity was higher in definite FH than in non-definite FH patients independently of LDL-C levels and statin treatment. These results highlight the particular phenotype of FH subjects among hypercholesterolemic patients. As increased Lp-PLA 2 activity suggests, FH patients exhibit higher arterial inflammation that may contribute to their high cardiovascular risk. Our results reinforce the potential beneficial role of statins pleiotropic effects and the need for proper identification and treatment of FH patients.

KEYWORDS: lipoprotein-associated phospholipase $\mathrm{A}_{2}$, familial hypercholesterolemia, dyslipidemia, cardiovascular disease, plaque vulnerability, vascular inflammation, cardiovascular risk, statin treatment, high density lipoprotein, low density lipoprotein. 


\section{INTRODUCTION}

\section{Lipoprotein-associated phospholipase $A_{2}$}

Lipoprotein-associated phospholipase $\mathrm{A}_{2}\left(\mathrm{Lp}-\mathrm{PLA}_{2}\right)$ is a calcium-independent enzyme mainly produced by macrophages. Lp-PLA 2 has been shown to play a key role in the development of atherosclerosis due to its pro-inflammatory and pro-oxidative effects ${ }^{1}$. Lp-PLA 2 is synthesized within the atherosclerotic plaque and circulates bound to LDL-C particles ${ }^{2}$. By the hydrolysis of oxidized LDL-C particles, Lp-PLA 2 generates bioactive lipid products (lysophosphatidylcholine and oxidized free fatty acids) which can activate and sustain the atherosclerosis process $^{3,4}$. Lp-PLA 2 is also implicated in endothelial dysfunction ${ }^{5}$, plaque vulnerability ${ }^{6,7,8}$ and has been associated with inflammation within the atherosclerotic plaque ${ }^{9}$. Furthermore, elevated Lp-PLA 2 levels were related to increased risk of coronary disease, stroke, and vascular mortality in several large scale prospective studies ${ }^{10}$.

However, little data exists in the specific population of patients with familial hypercholesterolemia (FH) which is an autosomal dominant lipoprotein metabolism disorder characterized by elevated plasma levels of low-density lipoprotein cholesterol (LDL-C) ${ }^{11}$. FH results from genetic heterozygous (heFH) or homozygous (hoFH) mutation in the low density lipoprotein receptor gene $(L D L R)$, apolipoprotein $\mathrm{B}-100$ gene $(A P O B)$ or proprotein convertase subtilisin/kexin type 9 gene $(P C S K 9)^{11}$. FH patients exhibit early atherosclerotic lesions ${ }^{12,13}$ with premature CVD compared to non-FH patients ${ }^{14,15}$. Prevalence of CVD among heFH has been estimated to be about $33 \%^{16}$ with a CVD increased risk by 8 to 17 - fold vs. non-FH subjects. In patients untreated with statins, angina and acute myocardial infarctions can be observed early in life, even before 40 years old ${ }^{17}$.

Our aim was to evaluate Lp-PLA 2 activity in a population of hypercholesterolemic patients with and without a clinical confirmed definite FH.

\section{MATERIAL AND METHODS}

\section{Study population}

Patients were consecutively recruited at our outpatient clinic (Cardiovascular Prevention Unit, Institute of Cardiometabolism and Nutrition, La Pitié-Salpêtrière-Charles Foix University Hospital, APHP, Paris, France) between June 2014 and June 2015. Only subjects with hypercholesterolemia were eligible for enrolment in this study. Hypercholesterolemia was 
defined according to patient's records as: $\mathrm{LDL}-\mathrm{C}>4.14 \mathrm{mmol} / \mathrm{L}$ or/and treatment with statin. FH groups and Dutch Lipid Clinic Score were determined using patient's files. Patients were included and divided into two subgroups:

- Definite FH (DFH) group defined according to the Dutch Lipid Clinic Network criteria $^{18,19}$ with a score $\geq 8$;

- Non-definite FH (NDFH) group of patients with Dutch Lipid Clinic Network criteria score $<8$.

Exclusion criteria were: LDL-C $\leq 1.3 \mathrm{mmol} / \mathrm{L}$ without lipid lowering treatment, high-density lipoprotein cholesterol $(\mathrm{HDL}-\mathrm{C}) \geq 2.6 \mathrm{mmol} / \mathrm{L}$ or $\leq 0.39 \mathrm{mmol} / \mathrm{L}$; triglycerides $(\mathrm{TG}) \geq 11.4$ $\mathrm{mmol} / \mathrm{L}$; fasting glucose $\geq 10 \mathrm{mmol} / \mathrm{L}$; history or treatment of thyroid disease; $\mathrm{FH}$ homozygous status. The aim for those exclusions was to define a homogenous population of patients with hypercholesterolemia.

All patients underwent routine clinical examination and biological assessments. In addition, Lp-PLA 2 activity was assessed. Arterial hypertension (AH) was defined as arterial blood pressure $(\mathrm{BP})>140 / 90 \mathrm{mmHg}$ and/or antihypertensive treatment; type 2 diabetes (T2D) as fasting plasma glucose $>6.94 \mathrm{mmol} / \mathrm{L}$ and/or glucose lowering treatment. Cigarette smoking (yes/no), body mass index (BMI) (weight in kilograms divided by the square of height in meters) and waist circumference were also evaluated. The study was carried out according to the principles outlined in the Declaration of Helsinki. Approval of the local Ethics Committee was obtained and informed consent was signed by all participants.

\section{Laboratory methods}

\section{Lipid analysis}

Fresh venous blood was collected in gel-containing Vacutainer ${ }^{\circledR}$ tubes (Becton-Dickinson, Plymouth, UK), then centrifuged at $4,500 \mathrm{rpm}$ at $4^{\circ} \mathrm{C}$ for 10 minutes.

Fresh serum lipids were analysed by using routine methods on a Konelab 30i analyser (Thermo Electron Corporation). TG were measured by using an enzymatic method with colorimetric detection (Diasys France Condom) ${ }^{20}$. Total cholesterol (TC), direct LDL-C and direct HDL-C were determined using automated enzymatic methods (Konelab Thermo Fisher Scientifics, Asnières sur Seine, France) $)^{21,22,23}$. LDL-C was calculated by the Friedewald 
formula when $\mathrm{TG}<3.9 \mathrm{mmol} / \mathrm{L}^{24}$ and directly dosed when TG were between 3.9 and 11.4 $\mathrm{mmol} / \mathrm{L}$.

ApoA-I, apoB and Lp(a) were measured by immunonephelometry using anti-ApoA-I, antiApoB and anti-apo(a) antisera and a BN II nephelometer analyser from Siemens (Siemens Healthcare Diagnostics S.A.S, Saint Denis France; inter- and intra-assay coefficients of variation $<4 \%)^{25}$.

\section{Measurement of lipoprotein-associated phospholipase $A_{2}\left(L p-P L A_{2}\right)$ activity}

Measurement of Lp-PLA 2 activity was performed with automated colorimetric method on Konelab 30i analyser, by using a rate reaction assay with 1-myristoyl-2-(4nitrophenylsuccinyl) phosphatidylcholine as substrate (Diadexus Inc. South San Francisco. CA. Eurobio, France). Units were expressed as nmol platelet activating factor (PAF) hydrolysed per minute per $\mathrm{mL}$ of serum $(\mathrm{nmol} / \mathrm{min} / \mathrm{mL})^{26}$. All assays were performed in the Department of Metabolic Biochemistry of Pitié-Salpêtrière - Charles Foix Hospital.

\section{Statistical analysis}

All continuous variables were described by their mean \pm standard deviation (SD) and proportions (\%) for categorical variables. The differences between groups were evaluated by Student's t test for continuous variables and $\chi^{2}$ test for categorical variables. Correlations between Lp-PLA 2 and lipid parameters were assessed using Pearson's correlation coefficient except for $\mathrm{Lp}(\mathrm{a})$ and TG where Spearman's rank correlation coefficients were provided. Multivariate linear regression analysis was used to assess the independent contribution of the variables. A p value $<0.05$ was considered significant. JMP® Statistical Software, Version 11 , SAS Institute Inc., Cary, NC, was used.

\section{RESULTS}

Our population consisted of 469 subjects. Among them, 118 (25.1\%) were classified into the definite FH group. Among DFH subjects, 51 had a known heterozygous mutation of $L D L R$, $A P O B$ or $P C S K 9$ gene. The clinical and biochemical characteristics of the whole population, as well as in DFH and in NDFH subjects are shown in Table 1. The mean Lp-PLA 2 activity of the whole population was $187.3 \pm 51.2 \mathrm{nmol} / \mathrm{min} / \mathrm{mL}$, with a significant difference between 
males and females $(195.9 \pm 48.5$ vs. $178.0 \pm 52.4 \mathrm{nmol} / \mathrm{min} / \mathrm{mL}$ respectively, $\mathrm{p} 0.0001$, data not shown). No difference in Lp-PLA 2 levels was found in the DFH group among subjects with known mutations and subjects without known mutations $(210.1 \pm 50.5$ and $203.8 \pm 57.5$ $\mathrm{nmol} / \mathrm{min} / \mathrm{mL}$ respectively, p 0.5330, Additional Figure 1).

Lp-PLA 2 activity was significantly higher in DFH subjects than it was in NDFH subjects $(206.5 \pm 54.5$ vs $180.8 \pm 48.4 \mathrm{nmol} / \mathrm{min} / \mathrm{mL}, \mathrm{p}<0.0001)$. DFH subjects were significantly younger than NDFH and less likely to suffer from diabetes or hypertension. Moreover, DFH subjects also exhibited lower HbA1c, TG, ApoA-1 levels, blood fasting glucose and blood pressure (BP) levels than NDFH. In opposite, they had higher TC, LDL-C and ApoB levels than NDFH subjects. Values of HDL-C and Lp(a) as well as the percentage of patients under statin treatment were identical in both groups.

Table 1. Whole population, definite familial hypercholesterolemia (DFH) and non-definite FH (NDFH) subgroups characteristics.

\begin{tabular}{|c|c|c|c|c|}
\hline Characteristics & All subjects & DFH & NDFH & $\mathbf{p}^{\mathbf{a}}$ \\
\hline $\mathrm{n}$ & 469 & 118 & 351 & \\
\hline Age, years & $59 \pm 14$ & $50 \pm 16$ & $62 \pm 11$ & $<0.0001$ \\
\hline Sex, men $(\%)$ & $243(52)$ & $60(50.9)$ & $183(52.1)$ & 0.8084 \\
\hline Lp-PLA 2 activity, $\mathrm{nmol} / \mathrm{min} / \mathrm{mL}$ & $187.3 \pm 51.2$ & $206.5 \pm 54.5$ & $180.8 \pm 48.4$ & $<\mathbf{0 . 0 0 0 1}$ \\
\hline \multicolumn{5}{|l|}{ Cardiovascular risk factors } \\
\hline Current smoking, n (\%) & $88(19)$ & $20(17.0)$ & $68(19.4)$ & 0.5096 \\
\hline Type 2 Diabetes, n (\%) & $74(16)$ & $6(5.1)$ & $68(19.4)$ & $<0.0001$ \\
\hline $\mathrm{HbA} 1 \mathrm{c}, \%$ & $5.9 \pm 0.60$ & $5.68 \pm 0.55$ & $5.96 \pm 0.60$ & $<0.05$ \\
\hline Arterial Hypertension, n (\%) & $195(42)$ & $21(17.8)$ & $174(49.7)$ & $<0.0001$ \\
\hline Systolic BP, mmHg & $116.7 \pm 12.8$ & $112.7 \pm 12.2$ & $118 \pm 12.8$ & $<0.0001$ \\
\hline \multicolumn{5}{|l|}{ Treatment } \\
\hline Antihypertensive treatment, n (\%) & $186(40)$ & $19(16)$ & $167(48)$ & $<0.0001$ \\
\hline Statins, n $(\%)$ & $332(71.0)$ & $90(76.3)$ & $242(69.0)$ & 0.1301 \\
\hline Ezetimibe, n (\%) & $75(16)$ & $31(26.3)$ & $44(12.5)$ & $<0.001$ \\
\hline \multicolumn{5}{|l|}{ Lipid profile } \\
\hline Total Cholesterol, mmol/L & $5.89 \pm 1.58$ & $6.34 \pm 1.96$ & $5.75 \pm 1.41$ & $<0.001$ \\
\hline LDL-Cholesterol, mmol/L & $3.77 \pm 1.5$ & $4.36 \pm 1.92$ & $3.60 \pm 1.26$ & $<0.0001$ \\
\hline HDL-Cholesterol, mmol/L & $1.37 \pm 0.44$ & $1.42 \pm 0.43$ & $1.37 \pm 0.45$ & 0.2830 \\
\hline Triglycerides, mmol/L & $1.65 \pm 1.32$ & $1.25 \pm 0.75$ & $1.81 \pm 1.45$ & $<0.0001$ \\
\hline Apolipoprotein A-1, mg/dL & $159.3 \pm 26.7$ & $155.1 \pm 27.4$ & $160.7 \pm 26.3$ & $<0.05$ \\
\hline Apolipoprotein B, mg/dL & $112.4 \pm 32.6$ & $121.4 \pm 40.9$ & $109.4 \pm 28.7$ & $<0.001$ \\
\hline $\mathrm{Lp}(\mathrm{a}), \mathrm{mg} / \mathrm{dL}$ & $43.2 \pm 46.0$ & $40.82 \pm 44.0$ & $44.0 \pm 46.7$ & 0.5237 \\
\hline
\end{tabular}

${ }^{\text {a }}$ Student's $t$ test $\mathrm{p}$ value: DFH vs. NDFH groups. DFH: definite familial hypercholesterolemia; NDFH: nondefinite familial hypercholesterolemia; Lp-PLA2: Lipoprotein-associated phospholipase $\mathrm{A}_{2}$. BP: blood pressure; LDL: low density lipoprotein; HDL: high density lipoprotein. 
Table 2 displays Lp-PLA 2 univariate correlations between Lp-PLA 2 activity and lipid biomarkers. Lp-PLA 2 activity was strongly positively correlated with TC, LDL-C and ApoB and negatively with HDL-C and ApoA-1. No correlation was found with TG and Lp(a).

In DFH patients on statins, Lp-PLA 2 activity levels were different from non-definite FH patients on statins $(202.3 \pm 53.8$ vs $168.1 \pm 43.6 \mathrm{nmol} / \mathrm{min} / \mathrm{mL}, \mathrm{p}<0.0001$, Additional Figure 2).

Table 2. Univariate correlations between Lipoprotein-associated phospholipase $\mathrm{A}_{2}$ (Lp-PLA 2 ) activity and lipid profile in the whole hypercholesterolemic population.

\begin{tabular}{llr}
\hline \hline & \multicolumn{2}{c}{ Lp-PLA2 activity } \\
\cline { 2 - 3 } & \multicolumn{1}{c}{$\mathbf{r}$} & $\mathbf{p}$ \\
\cline { 2 - 3 } & & \\
Total Cholesterol, mmol/L & 0.44 & $<0.0001$ \\
LDL-Cholesterol, mmol/L & 0.57 & $<0.0001$ \\
HDL-Cholesterol, mmol/L & -0.31 & $<0.0001$ \\
Triglycerides, mmol/L & $-0.05^{\mathrm{a}}$ & $\mathrm{NS}$ \\
Apolipoprotein A-1, $\mathbf{~ m g / d l ~}$ & -0.43 & $<0.0001$ \\
Apolipoprotein B, $\mathbf{~ m g / d l ~}$ & 0.57 & $<0.0001$ \\
Lp(a), mg/dl & $0.04^{\mathrm{a}}$ & $\mathrm{NS}$ \\
& & \\
\hline \hline
\end{tabular}

LDL: low density lipoprotein; HDL: high density lipoprotein; NS: not significant. aby Spearman's rank correlation coefficients.

Partial correlation of Lp-PLA 2 with ApoB and LDL showed that LDL-C and ApoB remains associated with Lp-PLA 2 ( $\mathrm{r}$ adj ApoB $=0.12, \mathrm{p}<0.01 ; \mathrm{r}$ adj LDL-C $=0.12, \mathrm{p}<0.01$ ). NonHDL-C did not remain correlated with Lp-PLA 2 when adjusted with LDL-C ( $\mathrm{r}$ adj LDL-C = $0.03, \mathrm{p} 0.86)$.

In a multivariate analysis, definite definite FH diagnosis as well as LDL-C, HDL-C and statin treatment remained correlated with Lp-PLA 2 independently of systolic BP. Inclusion of ApoB in the model in replacement of LDL-C did not change the outcome of the analysis.

Sex was independently related with Lp-PLA2 (Table 3). Separate multivariate analysis in DFH and NDFH patients showed minor differences in Lp-PLA 2 determinants but LDL-C and HDL-C remained significantly associated to Lp-PLA 2 (Additional Tables 1 and 2). 
Table 3. Variables independently associated with Lipoprotein-associated phospholipase $\mathrm{A}_{2}$ (Lp$\mathrm{PLA}_{2}$ ). Beta coefficient \pm standard error is shown.

\begin{tabular}{|c|c|c|c|}
\hline \multirow[b]{3}{*}{ Overall Model } & \multicolumn{3}{|c|}{ Lp-PLA2 } \\
\hline & $\mathbf{R}^{\mathbf{2}}$ & $\boldsymbol{\beta}$ & p \\
\hline & 0.55 & & $<0.0001$ \\
\hline Age, years & & $-0.33 \pm 0.15$ & 0.0240 \\
\hline $\operatorname{Sex}(\operatorname{men}=1)$ & & $19.44 \pm 3.91$ & $<0.0001$ \\
\hline Definite FH diagnosis $($ yes $=1)$ & & $9.36 \pm 4.48$ & $\mathbf{0 . 0 3 7 3}$ \\
\hline LDL-Cholesterol, mmol/L & & $17.93 \pm 1.43$ & $<0.0001$ \\
\hline HDL-Cholesterol, mmol/L & & $-29.48 \pm 4.34$ & $<\mathbf{0 . 0 0 0 1}$ \\
\hline Statins $($ yes $=1)$ & & $-9.30 \pm 4.50$ & 0.0394 \\
\hline Systolic BP, mmHg & & $-0.21 \pm 0.14$ & 0.1406 \\
\hline
\end{tabular}

FH: Familial Hypercholesterolemia; LDL: low density lipoprotein; HDL: high density lipoprotein; BP: blood pressure.

\section{DISCUSSION}

In this study, we found that Lp-PLA 2 activity in hypercholesterolemic subjects was independently higher in subjects with a clinically confirmed definite FH than in subjects with a non-definite FH according to Dutch Lipid Clinic Network criteria.

Our results extend the results of Tsimihodimos et al. ${ }^{27}$ who found higher Lp-PLA 2 activity in FH patients (carrying hetero and homozygous mutations) compared to non-FH hypercholesterolemic subjects and controls in a smaller population. Moreover, in our study, definite FH status and LDL-C levels both independently correlated to Lp-PLA 2 activity.

As observed here as well as in some previous studies ${ }^{5,27}$, Lp-PLA 2 activity correlates strongly and positively with LDL-C while negatively with HDL-C. The positive relationship with LDL-C may be explained by the fact that Lp-PLA 2 is mainly associated with apoB-containing lipoproteins (primarily with LDL), i.e. $70-75 \%$ when expressed in mass, and 90-95\% when expressed in activity ${ }^{28,29,30}$. This difference in assay procedure could also explain why we found a negative correlation with HDL-C despite about $30 \%$ of Lp-PLA 2 being carried by HDL particles ${ }^{31}$. Several lines of evidence suggest that the Lp-PLA 2 roles in atherosclerosis pathophysiology may depend on the type of lipoprotein particles with which it is associated $t^{32}$. It seems that only LDL-associated Lp-PLA 2 exerts pro-inflammatory activity while HDL-associated Lp-PLA 2 seems to have an anti-atherogenic role ${ }^{33}$. HDL prevents or inhibits the formation of LDL-derived oxidized phospholipids ${ }^{34}$ by the action of at least four specific enzymes present on its surface, including HDL-associated Lp-PLA 2 . Since oxidized 
phospholipids are the target of hydrolysis by Lp-PLA 2 , its activity can be reduced by increasing HDL concentration.

The inverse relationship between Lp-PLA 2 activity and HbA1c was also observed in previous studies $^{35,36}$. It may be explained by the distribution of Lp-PLA 2 among lipoprotein particles. In diabetic subjects ${ }^{37}$ in particular, Lp-PLA 2 is associated mainly with HDL particles and the Lp-PLA 2 glycosylation process leads to a greater activity of HDL-associated Lp-PLA ${ }_{2}{ }^{38}$.

While mendelian randomization studies may suggest otherwise ${ }^{39}$, there are some evidence for

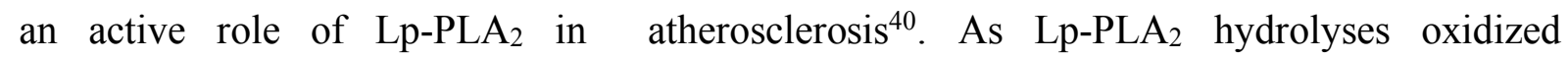
phospholipids in LDL-C particles to release oxidized fatty acids at the sn-2 position and lysophosphatidylcholine ${ }^{9}$ its activity can enhance plaque inflammation ${ }^{9}$. Hence, upregulation of Lp-PLA 2 has been demonstrated within the plaque necrotic core and in macrophages prone to rupture plaques ${ }^{41}$. Inflamed vulnerable plaques have been associated with a higher prevalence of coronary heart disease ${ }^{42,43}$ in the general population and increased circulating Lp-PLA 2 levels have been associated with higher plaque vulnerability ${ }^{8}$. Concerning FH, Caballero et al. ${ }^{44}$ found an increased prevalence of lipid-rich atherosclerotic plaques in $\mathrm{FH}$ using magnetic resonance imaging. Moreover, Van Den Oord et al. ${ }^{45}$ found that FH subjects more frequently exhibited atherosclerotic plaques neovascularization, a sign of plaque vulnerability. Along with the early and lifelong exposure to elevated LDL-C levels, those observations of more vulnerable plaques in $\mathrm{FH}$ patients could partially explain why $\mathrm{FH}$ patients develop premature symptomatic atherosclerosis. Our study suggests that the increased CVD risk in patients with $\mathrm{FH}$ could be partly explained by the arterial wall inflammation associated with plaque vulnerability and witnessed by high circulating Lp-PLA 2 levels. This hypothesis may be hampered by the STABILITY trial ${ }^{46}$ failure to prove that pharmacological Lp-PLA 2 activity lowering could decrease cardiovascular events in a high risk population of patients. However, no specific data on FH patients within the STABILITY trial were published. Also, in another trial ${ }^{51}$, while the darapladib molecule inhibited necrotic core growth of human coronary plaques, it failed to prevent cardiovascular events in a phase III trial.

In our study, statin treatment was negatively correlated to Lp-PLA 2 levels independently of LDL-C and definite FH status. This is coherent with the well-known effect of statins which decrease Lp-PLA 2 in general populations ${ }^{47}$ but also in selected $\mathrm{FH}$ population ${ }^{48,49}$ Our study extend those results in a larger population of real life definite FH patients. Beyond their LDL$\mathrm{C}$ lowering effect, statins exhibit pleiotropic effects. One of them is to stabilize atherosclerotic 
plaques by reducing foam cell formation and inflammatory process and by inhibiting the macrophages matrix metalloproteinases production ${ }^{50}$. High Lp-PLA 2 levels observed in our population may also be explained by the fact that only three quarters of definite FH subjects were under statin treatment. Our results further reinforce the concept that cardiovascular protection with statins may be partially explained by anti-inflammatory effects, perhaps on Lp-PLA 2 especially.

Our study exhibits some limitations. First, it is a cross sectional study and therefore we cannot determine causality. Then, we did not analyse the different lipoproteins particles in our study. Also, we did not measure Lp-PLA 2 mass, but Lp-PLA 2 activity has several technical advantages $^{30}$ including in the pre-analytic phase that makes it more easy to use in clinical practice. Another limit is that without the certainty of genetic diagnosis, it can be assumed that a variable percentage of FH patients were attributed to the NDFH group. This however did not prevent us from finding statistical differences between the groups.

\section{CONCLUSION}

In a population of hypercholesterolemic patients, we found that Lp-PLA 2 activity was higher in patients with a clinically confirmed definite FH independently of LDL-C levels and statin treatment in comparison with subjects with a non-definite FH according to Dutch Lipid Clinic Network criteria. These results highlight the particular phenotype of FH within the vast population of patients with hypercholesterolemia. In addition to early and lifelong elevated LDL-C, the high levels of arterial inflammation may also be involved in the premature onset of CVD in FH patients. Their high cardiovascular risk can be prevented by adequate therapeutic strategies using statin anti-inflammatory pleiotropic effects. Our results also reinforce the need for proper identification of this disease which affects $1 / 200$ people in Western countries.

\section{ACKNOWLEDGEMENTS}

This research did not receive any specific grant from funding agencies in the public, commercial, or not-for-profit sectors. 


\section{Author contributions}

AM: study conception, study realization, statistics and manuscript writing; DR: study conception, study supervision, statistics and manuscript supervision; RB: data collection and analysis, manuscript reviewing and scientific supervision; DBR: manuscript reviewing and scientific supervision; DN: statistics and manuscript supervision; MA: manuscript reviewing; EB: manuscript reviewing; PG: manuscript reviewing and supervision.

All authors have approved the final article.

\section{ACRONYMS}

Adj: adjusted. AH: arterial hypertension. $A P O B$ : apolipoprotein B-100 gene. BMI: body mass index. BP: blood pressure. CVD: cardiovascular disease. DFH: definite familial hypercholesterolemia (group). FH: familial hypercholesterolemia. HDL-C: high-density lipoprotein cholesterol. LDL-C: low-density lipoprotein cholesterol. LDLR: low density lipoprotein receptor gene. Lp-PLA 2 : lipoprotein-associated phospholipase $\mathrm{A}_{2}$. NDFH: nondefinite familial hypercholesterolemia (group). PCSK9: proprotein convertase subtilisin/kexin type 9 gene. T2D: type 2 diabetes. TC: total cholesterol. TG: triglycerides. 


\section{APPENDIX}

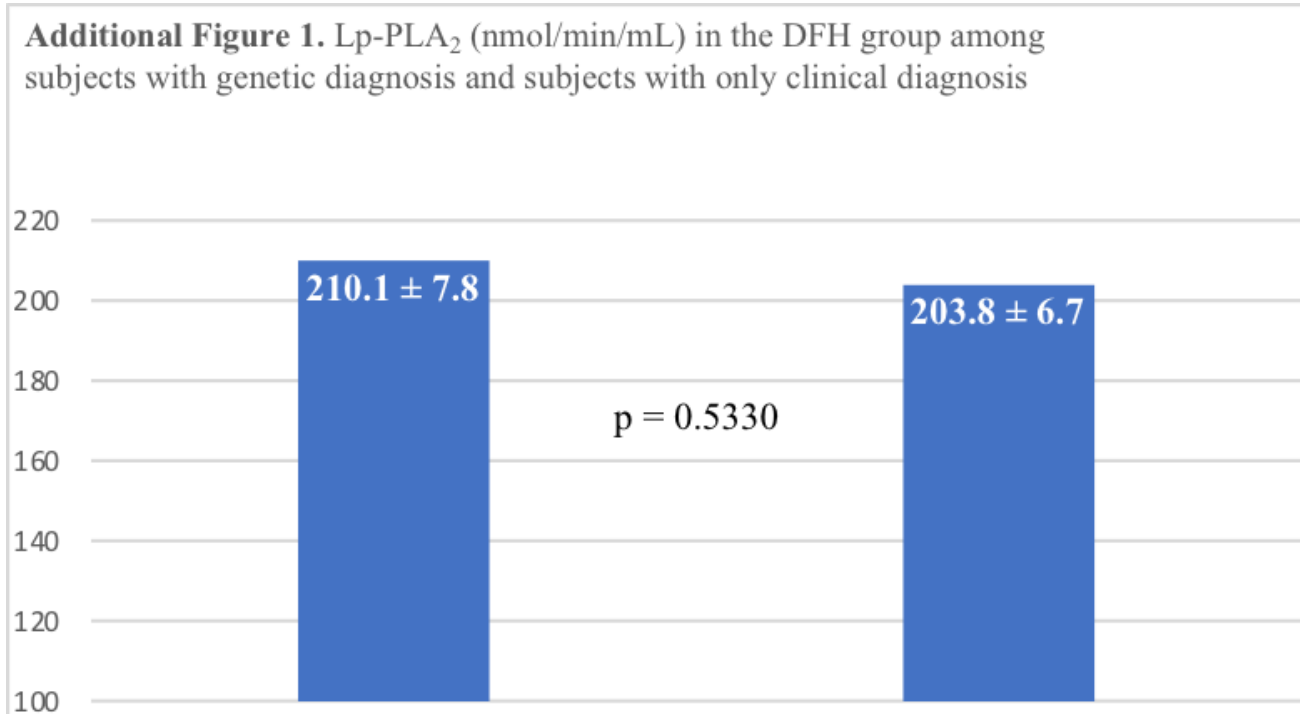

100

Lp-PLA $A_{2}$ : Lipoprotein-associated phospholipase $\mathrm{A}_{2}$; DFH: definite familial hypercholesterolemia.

Additional Figure 2. Lp-PLA $2(\mathrm{nmol} / \mathrm{min} / \mathrm{mL})$ among hypercholesterolemic subjects in statin treatment with and without definite $\mathrm{FH}$.

220

200

$202.3 \pm 53.8$

180

160

140

120

100

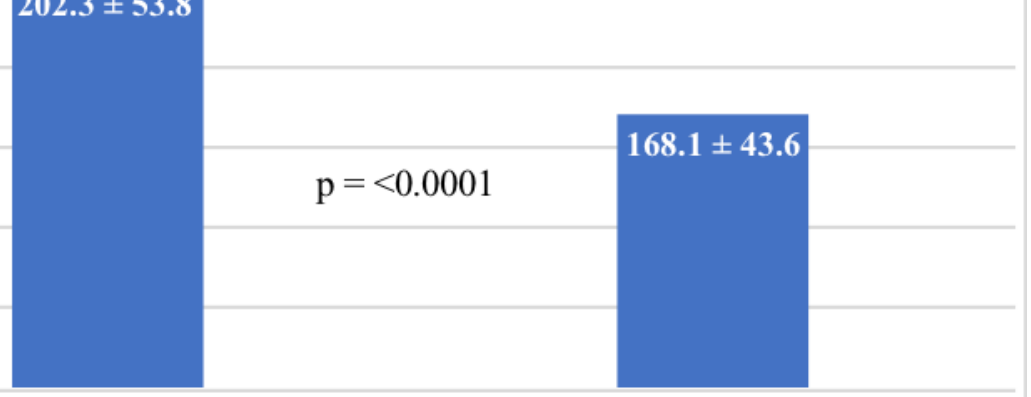

Lp-PLA $A_{2}$ : Lipoprotein-associated phospholipase $\mathrm{A}_{2}$;

DFH: definite familial hypercholesterolemia;

NDFH: non-definite familial hypercholesterolemia. 
Additional Table 1. Variables independently associated with Lipoprotein-associated phospholipase $\mathrm{A}_{2}$ (Lp-PLA $)$ in non- definite FH group. Beta coefficient \pm standard error is shown.

\begin{tabular}{|c|c|c|c|}
\hline \multirow[b]{3}{*}{ Overall Model } & \multicolumn{3}{|c|}{ Lp-PLA2 } \\
\hline & $\mathbf{R}^{2}$ & $\boldsymbol{\beta}$ & $\mathbf{p}$ \\
\hline & 0.55 & & $<0.0001$ \\
\hline Age, years & & $-0.09 \pm 0.18$ & 0.6175 \\
\hline $\operatorname{Sex}(\operatorname{men}=1)$ & & $21.63 \pm 4.30$ & $<0.0001$ \\
\hline LDL-Cholesterol, mmol/L & & $21.38 \pm 1.98$ & $<0.0001$ \\
\hline HDL-Cholesterol, mmol/L & & $-28.27 \pm 4.80$ & $<0.0001$ \\
\hline Statins $($ yes $=1)$ & & $-10.26 \pm 5.40$ & 0.0586 \\
\hline Systolic BP, mmHg & & $0.003 \pm 0.15$ & 0.9826 \\
\hline
\end{tabular}

FH: Familial Hypercholesterolemia; LDL: high density lipoprotein; HDL: high density lipoprotein; BP: blood pressure.

Additional Table 2. Variables independently associated with Lipoprotein-associated phospholipase $\mathrm{A}_{2}\left(\mathrm{Lp}-\mathrm{PLA} \mathrm{A}_{2}\right)$ in definite FH group. Beta coefficient \pm standard error is shown.

\begin{tabular}{|c|c|c|c|}
\hline \multirow[b]{3}{*}{ Overall Model } & \multicolumn{3}{|c|}{ Lp-PLA2 } \\
\hline & $\mathbf{R}^{\mathbf{2}}$ & $\boldsymbol{\beta}$ & $\mathbf{p}$ \\
\hline & 0.55 & & $<0.0001$ \\
\hline Age, years & & $-0.56 \pm 0.26$ & 0.0292 \\
\hline $\operatorname{Sex}(\operatorname{men}=1)$ & & $9.61 \pm 8.49$ & 0.2601 \\
\hline LDL-Cholesterol, mmol/L & & $14.02 \pm 2.22$ & $<0.0001$ \\
\hline HDL-Cholesterol, mmol/L & & $-41.98 \pm 9.52$ & $<0.0001$ \\
\hline Statins $($ yes $=1)$ & & $-4.56 \pm 9.35$ & 0.6267 \\
\hline Systolic BP, mmHg & & $-0.69 \pm 0.32$ & 0.0347 \\
\hline
\end{tabular}

FH: Familial Hypercholesterolemia; LDL: high density lipoprotein; HDL: high density lipoprotein; BP: blood pressure. 


\section{REFERENCES}

1. Bonnefont-Rousselot D. Lp-PLA2, a biomarker of vascular inflammation and vulnerability of atherosclerosis plaques. Ann Pharm Fr. 2016:74:190-197. doi:10.1016/j.pharma.2015.09.002.

2. Davis B, Koster G, Douet LJ, et al. Electrospray ionization mass spectrometry identifies substrates and products of lipoprotein-associated phospholipase A2 in oxidized human low density lipoprotein. J Biol Chem. 2008;283(10):6428-6437. doi:10.1074/jbc.M709970200.

3. Tew DG, Southan C, Rice SQJ, et al. Purification, Properties, Sequencing, and Cloning of a LipoproteinAssociated, Serine-Dependent Phospholipase Involved in the Oxidative Modification of Low-Density Lipoproteins. Arterioscler Thromb Vasc Biol. 1996;16(4):591-599. doi:10.1161/01.ATV.16.4.591.

4. Caslake MJ, Packard CJ, Suckling KE, Holmes SD, Chamberlain P, Macphee CH. Lipoproteinassociated phospholipase A2, platelet-activating factor acetylhydrolase: A potential new risk factor for coronary artery disease. Atherosclerosis. 2000;150(2):413-419. doi:10.1016/S0021-9150(99)00406-2.

5. Yang EH, McConnell JP, Lennon RJ, et al. Lipoprotein-associated phospholipase A2 is an independent marker for coronary endothelial dysfunction in humans. Arterioscler Thromb Vasc Biol. 2006;26(1):106111. doi:10.1161/01.ATV.0000191655.87296.ab.

6. Kolodgie FD, Burke AP, Skorija KS, et al. Lipoprotein-associated phospholipase A2 protein expression in the natural progression of human coronary atherosclerosis. Arterioscler Thromb Vasc Biol. 2006;26(11):2523-2529. doi:10.1161/01.ATV.0000244681.72738.bc.

7. Cola C, Clementi F, Biondi-Zoccai G, Sangiorgi G. From Carotid plaque biology to serologic markers of vulnerability to predict the risk of cerebrovascular events. Acta Chir Belg. 2007;107(2):129-142.

8. Weintraub HS. Identifying the Vulnerable Patient with Rupture-Prone Plaque. Am J Cardiol. 2008;101(12 SUPPL.). doi:10.1016/j.amjcard.2008.04.013.

9. Gonçalves I, Edsfeldt A, Ko NY, et al. Evidence supporting a key role of Lp-PLA2-generated lysophosphatidylcholine in human atherosclerotic plaque inflammation. Arterioscler Thromb Vasc Biol. 2012;32(6):1505-1512. doi:10.1161/ATVBAHA.112.249854.

10. Lp-PLA T, Collaboration S. Lipoprotein-associated phospholipase A 2 and risk of coronary disease, stroke, and mortality: collaborative analysis of 32 prospective studies. Lancet. 2010;375:1536-1544. doi:10.1016/S0140-6736(10)60319-4.

11. Hovingh GK, Davidson MH, Kastelein JJP, O’Connor AM. Diagnosis and treatment of familial hypercholesterolaemia. Eur Heart J. 2013;34(13):962-971. doi:10.1093/eurheartj/eht015.

12. Parrinello G, Barbagallo CM, Pinto A, et al. Carotid atherosclerosis in hypercholesterolemic patients: relationship with cardiovascular events. NutrMetab Cardiovasc. 2001;11(2):96-103.

13. Tanner FC, Boulanger CM, Luscher TF. Endothelium-derived nitric oxide, endothelin, and platelet vessel wall interaction: alterations in hypercholesterolemia and atherosclerosis. Semin Thromb Hemost. 
1993;19(2):167-175. doi:10.1055/s-2007-994021.

14. Descamps OS, Gilbeau JP, Leysen X, Van Leuven F, Heller FR. Impact of genetic defects on atherosclerosis in patients suspected of familial hypercholesterolaemia. Eur J Clin Invest.

2001;31(11):958-965. doi:10.1046/j.1365-2362.2001.00915.x.

15. Austin MA, Hutter CM, Zimmern RL, Humpries SE. Familial hypercholesterolemia and coronary heart disease: A HuGE association review. Am J Epidemiol. 2004;160(5):421-429. doi:10.1093/aje/kwh237.

16. Benn M, Watts GF, Tybjaerg-Hansen A, Nordestgaard BGBG. Familial hypercholesterolemia in the Danish general population: Prevalence, coronary artery disease, and cholesterol-lowering medication. $J$ Clin Endocrinol Metab. 2012;97(11):3956-3964. doi:10.1210/jc.2012-1563.

17. Scientific Steering Committe on behalf of the Simon Broome Register Group. Risk of fatal coronary heart disease in familial hypercholesterolaemia. BMJ. 1991;303(6807):893-896. doi:10.1136/bmj.303.6807.893.

18. Organization WH. Familial Hypercholesterolaemia (FM) - Report of a Second WHO Consultation.; 1999. doi:WHO/HGN/FH/CONS/99.2.

19. Nordestgaard BG, Chapman MJ, Humphries SE, et al. Familial hypercholesterolaemia is underdiagnosed and undertreated in the general population: Guidance for clinicians to prevent coronary heart disease. Eur Heart J. 2013;34(45):3478-3490. doi:10.1093/eurheartj/eht273.

20. Fossati P, Prencipe L. Serum triglycerides determined colorimetrically with an enzyme that produces hydrogen peroxide. Clin Chem. 1982;28(10):2077-2080.

21. Allain C, Poon L. Enzymatic Determination of Total Serum Cholesterol. Clin Chem. 1974;20(4):470475. http://www.clinchem.org/content/20/4/470.short.

22. Egloff M, Léglise D, Duvillard L, et al. [Multicenter evaluation on different analyzers of three methods for direct HDL-cholesterol assay]. Ann Biol Clin (Paris). 57(5):561-572. http://www.ncbi.nlm.nih.gov/pubmed/10518058. Accessed April 4, 2016.

23. Bayer P, Veinberg F, Couderc R, et al. [Multicenter evaluation of four homogenous LDL-cholesterol assays]. Ann Biol Clin. 2005;63(1):27-41.

http://www.ncbi.nlm.nih.gov/entrez/query.fcgi?cmd=Retrieve\&db=PubMed\&dopt=Citation\&list_uids=1 5689310.

24. Friedewald WT, Levy RI, Fredrickson DS. Estimation of the concentration of low-density lipoprotein cholesterol in plasma, without use of the preparative ultracentrifuge. Clin Chem. 1972;18(6):499-502. doi:10.1177/107424840501000106.

25. Albers JJ, Marcovina SM, Kennedy H. International federation of clinical chemistry standardization project for measurements of apolipoproteins A-I and B. II. Evaluation and selection of candidate reference materials. Clin Chem. 1992;38(5):658-662.

26. Caslake MJ, Packard CJ, Robertson M, et al. Lipoprotein-associated phospholipase A2, inflammatory biomarkers, and risk of cardiovascular disease in the Prospective Study of Pravastatin in the Elderly at 
Risk (PROSPER). Atherosclerosis. 2010;210(1):28-34. doi:10.1016/j.atherosclerosis.2009.10.041.

27. Tsimihodimos V, Karabina S-AP, Tambaki AP, et al. Altered distribution of platelet-activating factoracetylhydrolase activity between LDL and HDL as a function of the severity of hypercholesterolemia. $J$ Lipid Res. 2002;43(2):256-263. http://www.ncbi.nlm.nih.gov/pubmed/11861667. Accessed April 5, 2016.

28. Gazi I, Lourida ES, Filippatos T, Tsimihodimos V, Elisaf M, Tselepis AD. Lipoprotein-associated phospholipase A2 activity is a marker of small, dense LDL particles in human plasma. Clin Chem. 2005;51(12):2264-2273. doi:10.1373/clinchem.2005.058404.

29. Tselepis AD, Dentan C, Karabina S-AA, Chapman MJ, Ninio E. PAF-degrading acetylhydrolase is preferentially associated with dense LDL and VHDL-1 in human plasma. Catalytic characteristics and relation to the monocyte-derived enzyme. Arterioscler Thromb Vasc Biol. 1995;15(10):1764-1773. doi:10.1161/01.ATV.15.10.1764.

30. Donato LJ, Meeusen JW, Callanan H, Saenger AK, Jaffe AS. Advantages of the lipoprotein-associated phospholipase A2 activity assay. Clin Biochem. 2016;49(1):172-175. doi:10.1016/j.clinbiochem.2015.09.002.

31. Cao J, Hsu Y-H, Li S, Woods VL, Dennis EA. Structural basis of specific interactions of Lp-PLA2 with HDL revealed by hydrogen deuterium exchange mass spectrometry. J Lipid Res. 2013;54(1):127-133. doi:10.1194/jlr.M030221.

32. Tellis CC, Tselepis AD. Pathophysiological role and clinical significance of lipoprotein-associated phospholipase A(2) (Lp-PLA(2)) bound to LDL and HDL. Curr Pharm Des. 2014;20(40):6256-6269. http://www.ncbi.nlm.nih.gov/pubmed/24953389. Accessed April 6, 2016.

33. Marathe GK, Zimmerman GA, McIntyre TM. Platelet-activating factor acetylhydrolase, and not paraoxonase-1, is the oxidized phospholipid hydrolase of high density lipoprotein particles. J Biol Chem. 2003;278(6):3937-3947. doi:10.1074/jbc.M211126200.

34. Navab M, Berliner J a, Subbanagounder G, et al. HDL and the inflammatory response induced by LDLderived oxidized phospholipids. Arterioscler Thromb Vasc Biol. 2001;21(4):481-488. doi:10.1161/01.ATV.21.4.481.

35. Mayer O, Seidlerova J, Filipovsky J, et al. Unexpected inverse relationship between impaired glucose metabolism and lipoprotein-associated phospholipase A2 activity in patients with stable vascular disease. Eur J Intern Med. 2014;25(6):556-560. doi:10.1016/j.ejim.2014.05.010.

36. Onat A, Hergenç G, Can G, Uğur M, Nartop F. Dual activity of serum lipoprotein-associated phospholipase A(2) yielding positive and inverse associations with cardiometabolic risk. Clin Chem Lab Med. 2011;49(8):1349-1357. doi:10.1515/CCLM.2011.110.

37. Kujiraoka T, Iwasaki T, Ishihara M, et al. Altered distribution of plasma PAF-AH between HDLs and other lipoproteins in hyperlipidemia and diabetes mellitus. J Lipid Res. 2003;44(10):2006-2014. doi:10.1194/j1r.D300021-JLR200. 
38. Tselepis AD, Karabina SA, Stengel D, Piédagnel R, Chapman MJ, Ninio E. N-linked glycosylation of macrophage-derived PAF-AH is a major determinant of enzyme association with plasma HDL. J Lipid Res. 2001;42(10):1645-1654. http://www.ncbi.nlm.nih.gov/pubmed/11590221. Accessed May 16, 2016.

39. Ueshima H, Kadowaki T, Hisamatsu T, et al. Lipoprotein-associated phospholipase A2 is related to risk of subclinical atherosclerosis but is not supported by Mendelian randomization analysis in a general Japanese population. Atherosclerosis. 2016;246:141-147. doi:10.1016/j.atherosclerosis.2015.12.027.

40. Garza C, Montori V, McConnell J. Association between lipoprotein-associated phospholipase A 2 and cardiovascular disease: a systematic review. Mayo Clin. 2007;82(February):159-165.

http://www.sciencedirect.com/science/article/pii/S0025619611609920.

41. Sudhir K. Clinical review: Lipoprotein-associated phospholipase A2, a novel inflammatory biomarker and independent risk predictor for cardiovascular disease. J Clin Endocrinol Metab. 2005;90(5):31003105. doi:10.1210/jc.2004-2027.

42. Burke AP, Farb A, Malcolm GT, Liang Y-H, Smialek J, Virmani R. Coronary Risk Factors and Plaque Morphology in Men with Coronary Disease Who Died Suddenly. N Engl J Med. 1997;336(18):12761282. doi:10.1056/NEJM199705013361802.

43. Sidhu PS, Naoumova RP, Maher VM, et al. The extracranial carotid artery in familial hypercholesterolaemia: relationship of intimal-medial thickness and plaque morphology with plasma lipids and coronary heart disease. J Cardiovasc Risk. 1996;3(1):61-67. doi:10.1097/00043798199602000-00009.

44. Caballero P, Alonso R, Rosado P, et al. Detection of subclinical atherosclerosis in familial hypercholesterolemia using non-invasive imaging modalities. Atherosclerosis. 2012;222(2):468-472. doi:10.1016/j.atherosclerosis.2012.02.043.

45. Van Den Oord SCH, Akkus Z, Roeters van Lennep JE, et al. Assessment of subclinical atherosclerosis and intraplaque neovascularization using quantitative contrast-enhanced ultrasound in patients with familial hypercholesterolemia. Atherosclerosis. 2013;231(1):107-113.

doi:10.1016/j.atherosclerosis.2013.08.040.

46. Wallentin L, Held C, Armstrong PW, et al. Lipoprotein-Associated Phospholipase A2 Activity Is a Marker of Risk But Not a Useful Target for Treatment in Patients With Stable Coronary Heart Disease. $J$ Am Heart Assoc. 2016;5(6). doi:10.1161/JAHA.116.003407.

47. Braun LT, Davidson MH. Lp-PLA2: A New Target for Statin Therapy. Curr Atheroscler Rep. 2010;12(1):29-33. doi:10.1007/s11883-009-0074-y.

48. Ryu SK, Hutten BA, Vissers MN, Wiegman A, Kastelein JJP, Tsimikas S. Lipoprotein-associated phospholipase A2 mass and activity in children with heterozygous familial hypercholesterolemia and unaffected siblings: Effect of pravastatin. J Clin Lipidol. 2011;5(1):50-56. doi:10.1016/j.jacl.2010.11.001.

49. Saougos VG, Tambaki AP, Kalogirou M, et al. Differential effect of hypolipidemic drugs on lipoproteinassociated phospholipase A2. Arterioscler Thromb Vasc Biol. 2007;27(10):2236-2243. 
doi:10.1161/ATVBAHA.107.147280.

50. Davignon J. Beneficial cardiovascular pleiotropic effects of statins. Circulation. 2004;109(23 Suppl 1):III39-43. doi:10.1161/01.CIR.0000131517.20177.5a.

51. Serruys PW, García-García HM, Buszman P, et al. Effects of the direct lipoprotein-associated phospholipase A(2) inhibitor darapladib on human coronary atherosclerotic plaque. Circulation. 2008;118(11):1172-1182. doi:10.1161/CIRCULATIONAHA.108.771899. 